\title{
Comparison performance of split plug-in hybrid electric vehicle and hybrid electric vehicle using ADVISOR
}

\author{
Muhammad Ikram Mohd Rashid ${ }^{1, *}$, Hamdan Daniyal $^{1}$ and Danial Mohamed ${ }^{2}$ \\ ${ }^{1}$ Sustainable Energy \& Power Electronics Research Group(SuPER), Faculty of Electrical and \\ Electronics Engineering, Universiti Malaysia Pahang, 26600 Pekan, Pahang, Malaysia \\ ${ }^{2}$ Automotive Engineering Centre(AEC), Universiti Malaysia Pahang (UMP), 26600 Pekan, Pahang, \\ Malaysia
}

\begin{abstract}
Electric vehicle suffers from relatively short range and long charging times and consequently has not become an acceptable solution to the automotive consumer. The addition of an internal combustion engine to extend the range of the electric vehicle is one method of exploiting the high efficiency and lack of emissions of the electric vehicle while retaining the range and convenient refuelling times of a conventional gasoline powered vehicle. The term that describes this type of vehicle is a hybrid electric vehicle. Many configurations of hybrid electric vehicles have been designed and implemented, namely the series, parallel and power-split configurations. This paper discusses the comparison between Split Plug-in Hybrid Electric Vehicle(SPHEV) and Hybrid Electric Vehicle(HEV). Modelling methods such as physics-based Resistive Companion Form technique and Bond Graph method are presented with powertrain component and system modelling examples. The modelling and simulation capability of existing tools such as ADvanced VehIcle SimulatOR (ADVISOR) is demonstrated through application examples. Since power electronics is indispensable in hybrid vehicles, the issue of numerical oscillations in dynamic simulations involving power electronics is briefly addressed.
\end{abstract}

\section{Introduction}

A hybrid electric vehicle draws its propulsion power from an (Internal Combustion Engine)ICE and an electric motor, which can also operate as a generator to charge the onboard electrical energy storage device. Depending on the connectivity of the power sources to the load (wheels), the HEV may have one of the following drivetrain configurations: series hybrid, parallel hybrid or combined series-parallel hybrid [1].

A series-hybrid Fig. 1 only has the electric motor turning the drive-shaft while the ICE serves as an on-board electric generator to charge the batteries and/or to power the motor directly ('series' connection between the ICE the electric motor, resulting in an electric transmission of power to the wheels) [1].

\footnotetext{
* Corresponding author: mikramump@gmail.com
} 


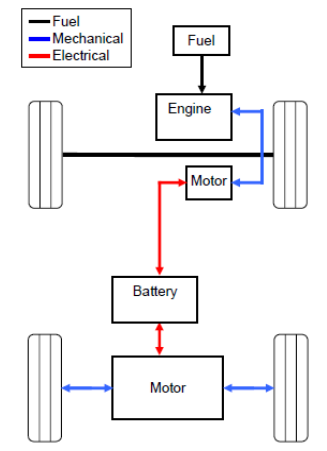

Fig. 1. Series-hybrid electric vehicle [2].

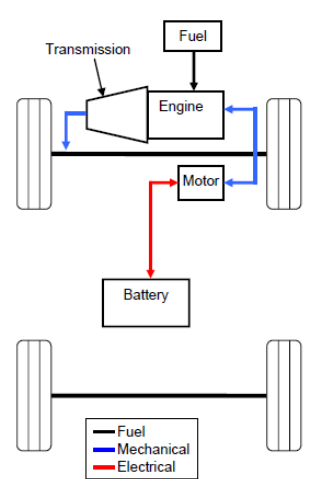

Fig. 2. Parallel-hybrid electric vehicle [2].

Instead, a parallel-hybrid vehicle Fig. 2 has the ICE turning the drive-shaft, just like a conventional vehicle, but the drive-shaft can also be turned by the electric motor ('parallel' connection of the ICE and motor to the drive shaft via some form of mechanical coupling and transmission) [1].

A hybrid vehicle typically has the motor-generator onboard the chassis, as in most production hybrids of today, the parallel "through the road" hybrid uses one motor for propulsion assist or to recharge the battery by loading the rear axle with the motor. In contrast, the series hybrid provides power to the wheels by a series path of energy conversion through the engine to the generator, battery, then the rear motor. Note that the series hybrid and through-the-road parallel hybrid can still propel the vehicle without the engine on, sourcing power for the rear motor from the battery [2].

In this paper addressed about comparison between modelling split hybrid electric vehicle and hybrid electric vehicle and simulate it using ADVISOR. All simulation was done by using ADVISOR and the results were discussed through this paper.

\section{HEV modeling using ADVISOR}

ADvanced VehIcle SimulatOR (ADVISOR) is a modelling and simulation tool developed by U.S. National Renewable Energy Laboratory (NREL) [4,5]. It can be used for the analysis of performance, fuel economy, and emissions of conventional, electric, hybrid electric, and fuel cell vehicles. The backbone of the ADVISOR model is the Simulink block diagram shown in Fig. 3, for a parallel HEV as an example. Each subsystem (block) of the block diagram has a Matlab file ( $m$-file) associated with it, which defines the parameters of that particular subsystem. The user can alter both the model inside the block as well as the $\mathrm{m}$-files associated with the block to suit the modelling needs. For example, the user may need a more precise model for the electric motor subsystem. A different model can replace the existing model as long as the inputs and the outputs are the same. On the other hand, the user may leave the model intact and only change the m-file associated with the block diagram. This is equivalent to choosing a different make of the same component (for example choosing a 12-Ah battery manufactured by Hawker-Genesis instead of a 6-Ah battery manufactured by Caterpillar). ADVISOR provides modelling flexibility for a user.

ADVISOR models fit empirical data obtained from the component testing to simulate a particular subsystem. In general, the efficiency and limiting performances define the operation of each component. For example, the ICE is modelled using an efficiency map that is obtained via experiments. The efficiency map of a Geo $1.0 \mathrm{~L}(43 \mathrm{~kW})$ engine is shown in Fig. 4. The maximum torque curve is also shown in this map. The engine cannot 
perform beyond this maximum torque constraint. Maximum torque change is another constraint to the engine subsystem. In other words, the model considers the inertia of the component in the simulation.

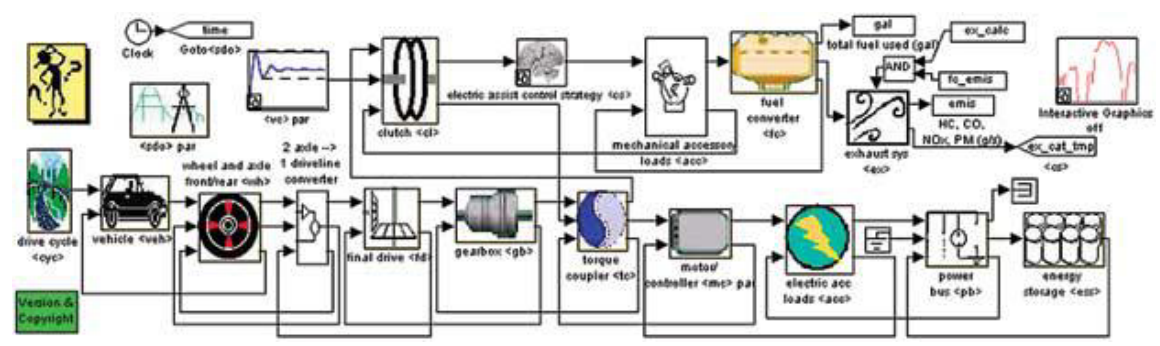

Fig. 3. Block diagram of parallel HEV in ADVISOR [3].

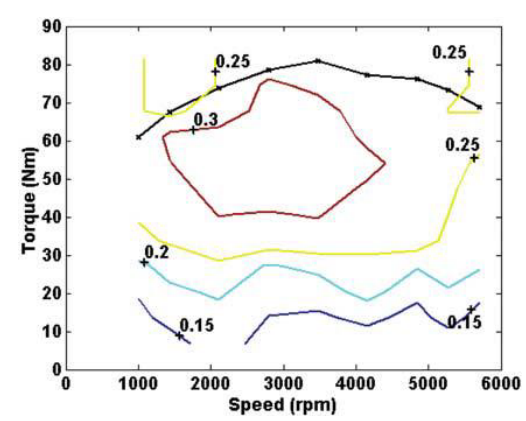

Fig. 4. Geo 1.0 L (43 kW) SI engine efficiency map model [3].

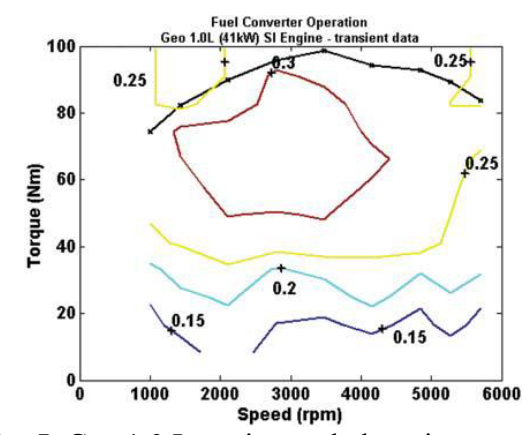

Fig. 5. Geo $1.0 \mathrm{~L}$ engine scaled to give a maximum power of $50 \mathrm{~kW}$ by linear alteration of torque characteristics.[3].

The program also allows for the linear scaling of components. For an ICE, this means linear scaling of the torque to provide the required maximum power. This type of scaling is valid only in the neighborhood near the actual parameter where the efficiency map for a slightly larger or smaller component would not change drastically. Scaling of the Geo ICE is shown in Fig. 5 so that the ICE gives a maximum power of $50 \mathrm{~kW}$ instead of the nominal $43 \mathrm{~kW}$.

In the latest version of ADVISOR, the functionality of the software was improved by allowing links to other software packages such as Ansoft Simplorer [6] and Synopsys Saber [7]. These powerful software packages allow for a more detailed look at the electric systems of the vehicle.

As an application example, ADVISOR is used to simulate a hybrid battery/ultracapacitor energy storage system. More extensive applications can be found in [8], where ADVISOR is used to model hybrid fuel cell/battery powertrain and hybrid fuel cell/ultracapacitor powertrain and simulate their fuel economy and performance. The concept of using a hybrid energy storage system consisting of a battery and an ultracapacitor (UC) is well known and well documented in literature [9,10]. The ultracapacitor provides and absorbs the current peaks, while the battery provides the average power required for the electric motor. This arrangement of hybrid energy storage in an HEV extends the life of the battery and allows the motor to operate more aggressively. Simulating such a system in ADVISOR allows the user to visualize the fuel economy benefit. At the same time, the program allows the user to design the best control strategy for the battery/ ultra-capacitor hybrid to improve the battery life and the overall system 
performance. Finally, the size of the components can be optimized and, thus, the cost and weight of the system can be reduced.

The default battery model in ADVISOR operates by requesting a specific amount of power from the battery as decided by the vehicle control strategy. Depending on the amount of power that the battery is able to supply, the battery module will send out the power available from the battery to the other subsystems. Due to the hybrid backward/forward simulation method of ADVISOR, the amount of power that the batteries are able and required to supply in a given time step is calculated in a single iteration. From this value, the battery model calculates the battery variables like current, voltage, and the battery temperature.

However, a hybrid battery/ultracapacitor energy storage system cannot be modeled within ADVISOR using the above default battery model. So, have to replace the energy storage model with a more complex model. Fortunately, the subsystem model in ADVISOR can be altered as long as the types of inputs and outputs to the rest of the vehicle are not altered. In the simulation, need to replace the battery model by a model of a combination of a battery and an ultra-capacitor connected to a local control strategy unit that splits the power demand between the battery and the ultra-capacitor. Detailed information about the control strategy is available in [9]. The block diagram representation of the system is shown in Fig. 6.

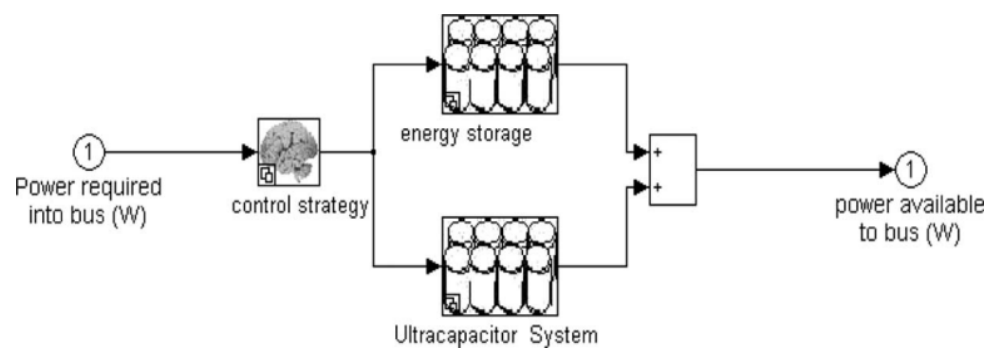

Fig. 6. Block diagram representation of new battery subsystem that consists of battery and ultracapacitor. Input/output relation with rest of the system is left unchanged [3].

The use of the model described gives the user a way to quickly and easily simulate the battery/ultra-capacitor subsystem in a vehicle environment. It allows the user to observe the benefit of using the ultra-capacitor on the fuel economy of the vehicle as well as the benefit to the battery by making the battery state of charge more even and by reducing the peaks of the battery current that the battery has to accept. It also allows the user to validate the system whether it operates as efficiently if the battery size were reduced. Finally, the user can optimize the battery/ultra-capacitor control strategy (in other words, how the power demand will be split) without having to think about the complexities of designing the power electronics to make this control system feasible. In addition, the system can be optimized before any system is built and the system cost and possible savings can be easily calculated at the early design stage. Once the control strategy is optimized, the actual dc/dc converter with the required control strategies can be integrated into the simulation using Saber or Ansoft Simplorer software [9].

\section{Propose System}

The overall objective of this paper is to define a performance for a Split PHEV shown in Fig. 7 by simulates powertrain of the system. Fig. 8 shows block diagram of the system. The results of these simulations should define how the vehicle can decrease fuel consumption, while maintaining low vehicle emissions. Because of the hybrid system, just 
operating an engine in its regions of high efficiency does not guarantee efficient vehicle operation. These results will not give the specific powertrain commands necessary to enable complete vehicle operation, and are meant only to define a literal strategy; that is, an understanding as to why the vehicle should operate in a certain way under the given conditions.
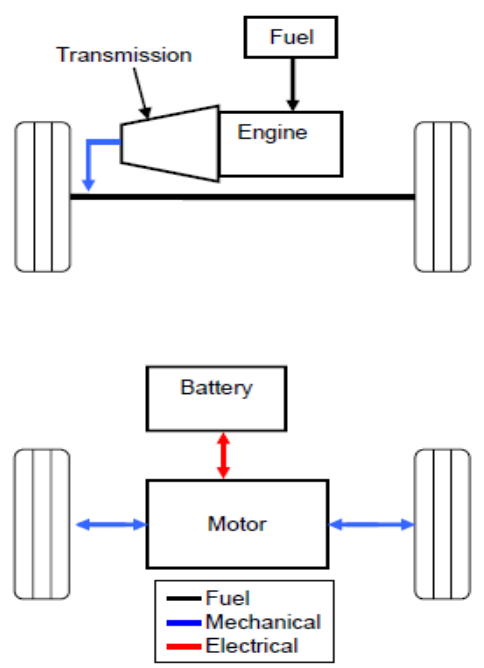

Fig.7. Split Plug-in Hybrid Electric Vehicle [2].

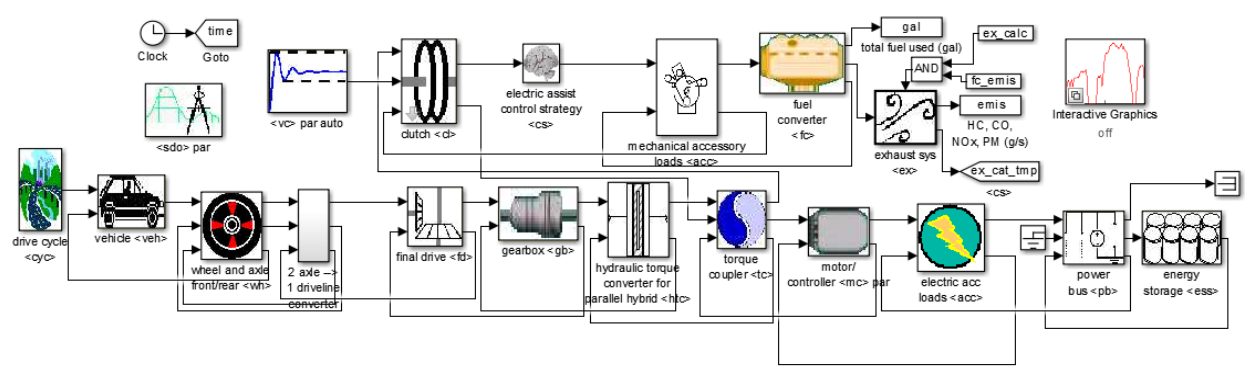

Fig. 8. Block diagram of Split PHEV in ADVISOR.

\section{Simulation Setup}

\subsection{Simulation configuration}

The system configuration was shown in Tables 1 and 2. Small car Produa Kancil was used in this simulation with default component and rear wheel system was installing the $10 \mathrm{~kW}$ electric vehicle conversion kit (Figs. 9 and 10). 

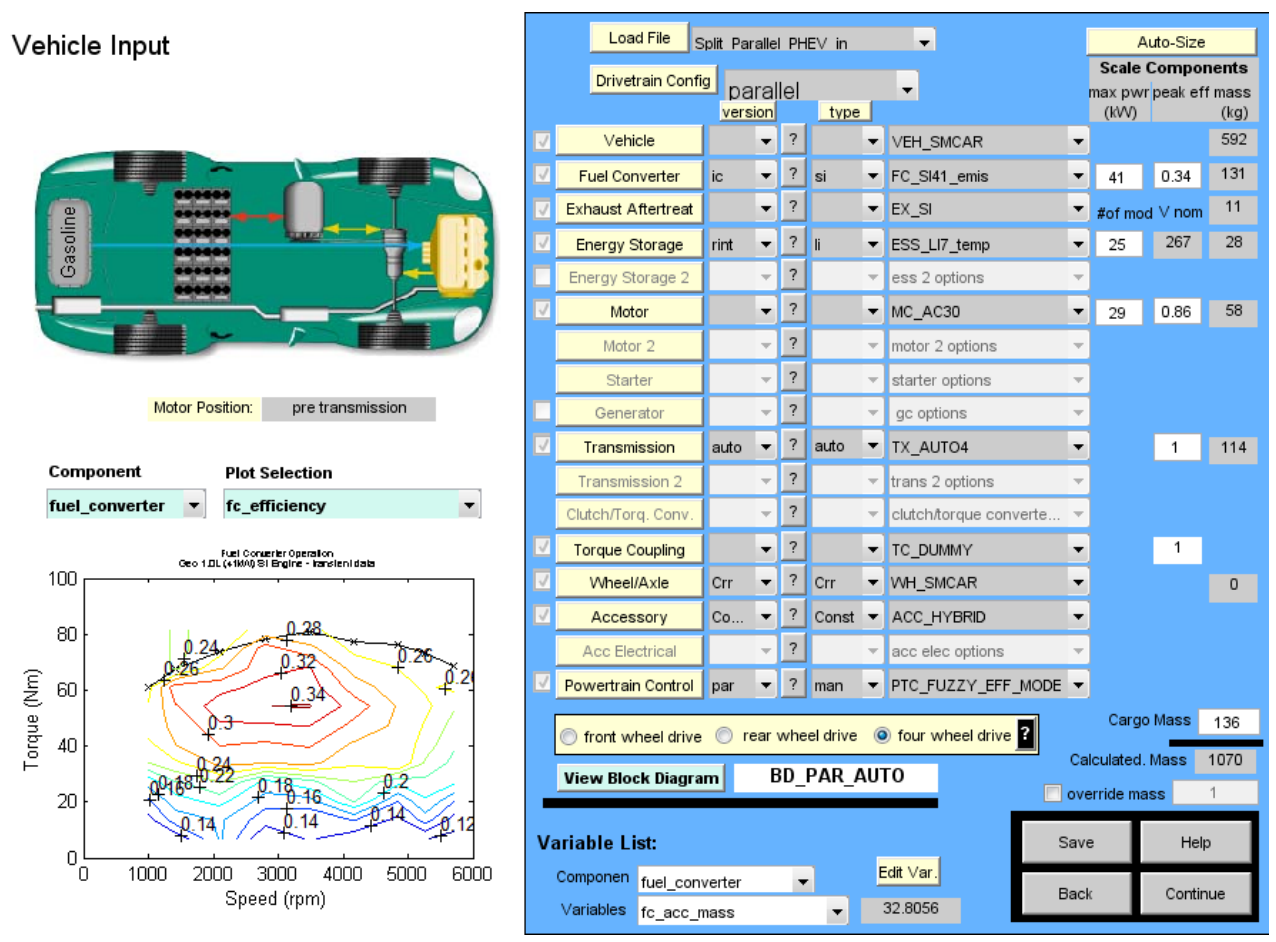

Fig. 9. Propose System: Split Plug-in hybrid.

Table 1. Split PHEV configurations.

\begin{tabular}{|c|c|}
\hline Component & Description \\
\hline Engine & 850CC Gasoline Engine \\
\hline Motor & 10kW AC Motor \\
\hline Battery & LifePO4 96V 60Ah \\
\hline Transmission & $\begin{array}{c}\text { 4 Speed on the front and Rear Axle } \\
\text { (Wheel distance 1385mm)Ratio: 10.6:1 }\end{array}$ \\
\hline Control Strategy & Propelling, Shifting and Breaking \\
\hline Weight & 550kg \\
\hline
\end{tabular}



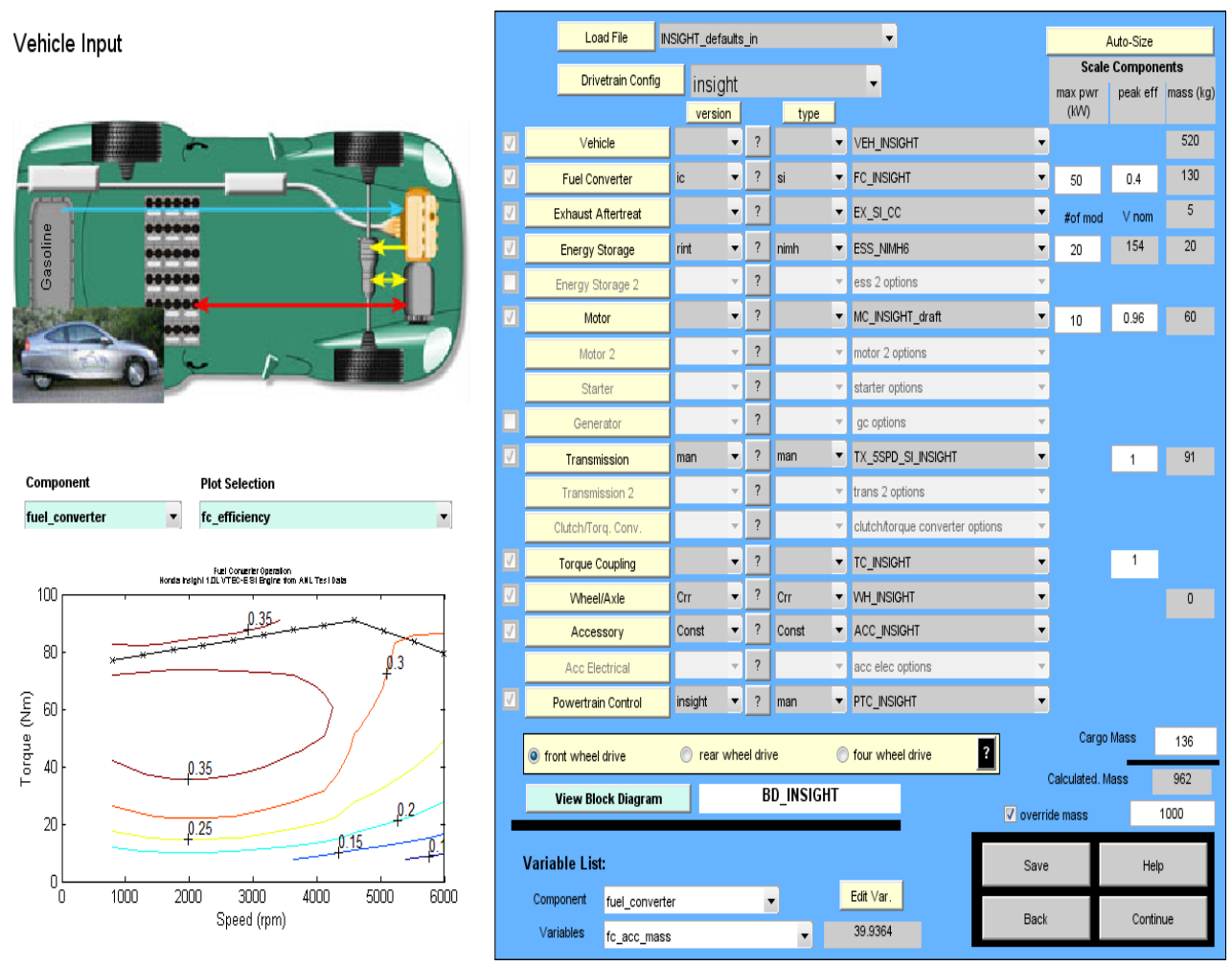

Fig. 10. Honda Insight Hybrid.

Table 2. Honda Insight Hybrid configuration.

\begin{tabular}{|c|c|}
\hline Component & Description \\
\hline Engine & 995CC Gasoline Engine \\
\hline Motor & 10kW Permanent Magnet \\
\hline Battery & Nickel Metal Hydride (Ni-MH) 144V \\
& 6.5Ah \\
\hline Transmission & $\begin{array}{c}\text { Front-Wheel Drive } \\
\text { Ratio: } 3.208\end{array}$ \\
\hline Control Strategy & Propelling, Shifting and Breaking \\
\hline Weight & 891kg \\
\hline
\end{tabular}

\section{Results and discussion}

The Graphs in Fig 11 shown the performance of propose split PHEV in ADVISOR. The patent of driving showed in first graph how drive cycle graph perform in speed versus distance. In the Fig 11 shown summary results for the propose system. Fuel consumption for this proposes vehicle is approximately $35 \mathrm{~km} / \mathrm{L}$. The distance for this test is about $12 \mathrm{~km}$ on city highway road.

Fig 12 shown comparison performance between propose PHEV and Honda Insight HEV. The results shown that the propose PHEV have better performance compare to Honda Insight. States of Charge (SOC) for propose PHEV is red line and Honda Insight $\mathrm{HEV}$ is blue line. Honda Insight HEV used more fuel per km compare to propose PHEV. 
Honda Insight fuel consumption approximately $29 \mathrm{~km} / \mathrm{L}$. The propose PHEV lead about $6 \mathrm{~km} / \mathrm{L}$ compare to Honda Insight base from the ADVISOR simulation.
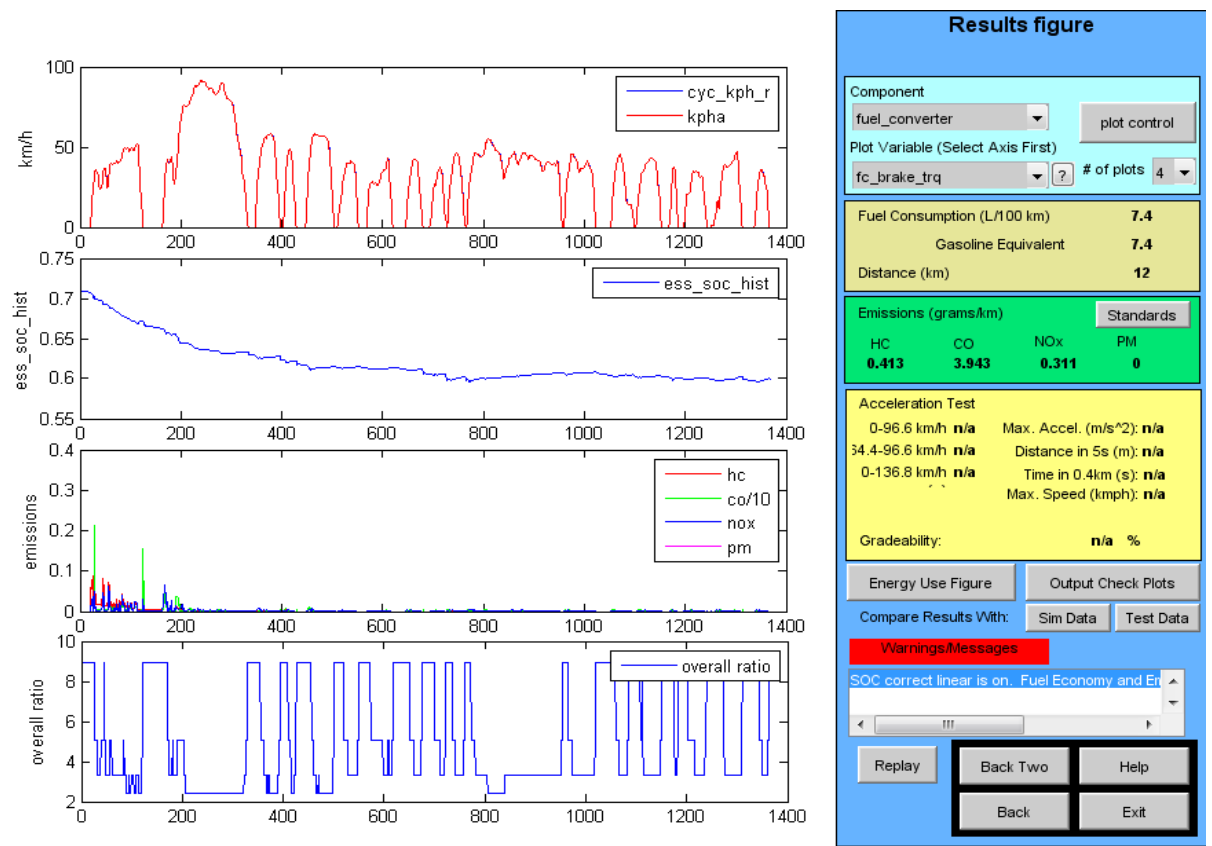

Fig. 11. Simulation result for Split Plug-in Hybrid.
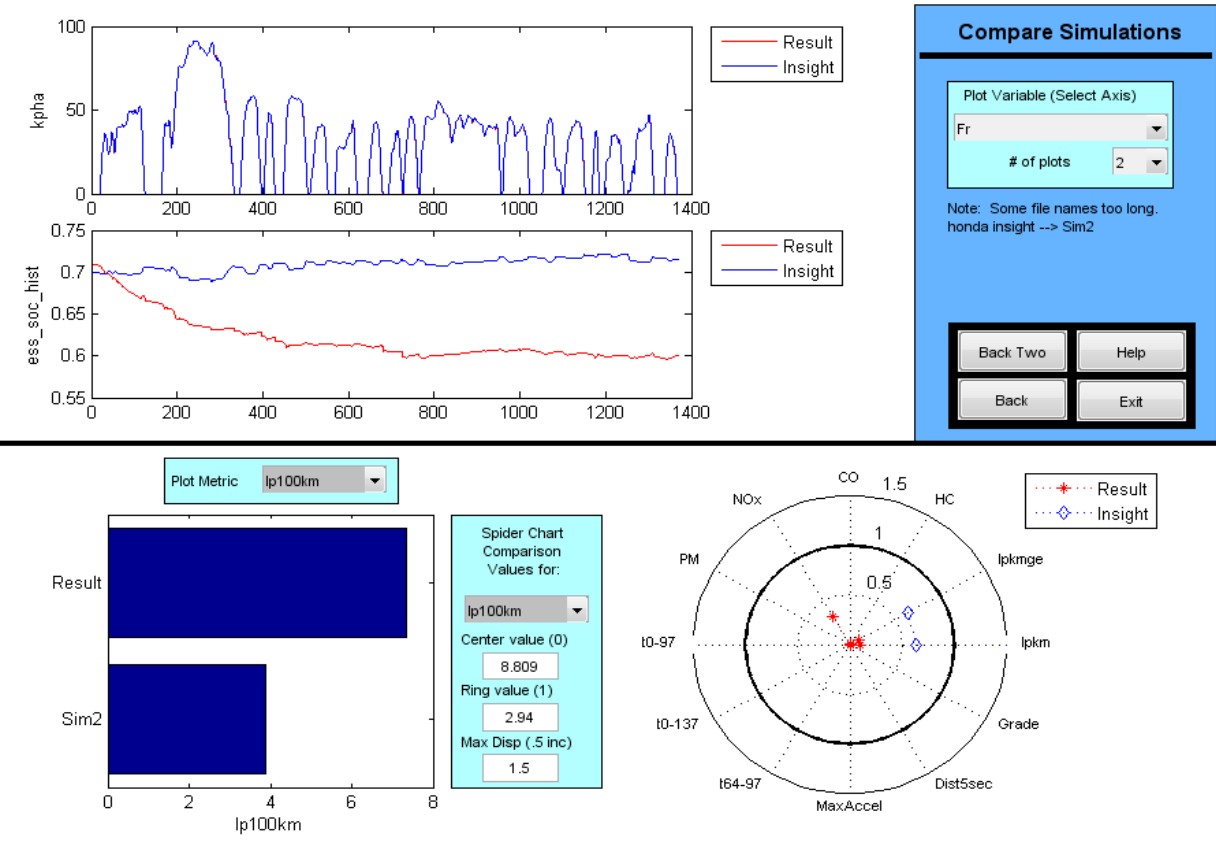

Fig. 12. Simulation results comparison for Split Plug-in Hybrid and Honda Insight Hybrid 


\section{Conclusions}

In this paper, a dynamic model for the split PHEV was developed and compared with Honda Insight HEV. The results show that propose PHEV have better performance compare to Honda Insight HEV. These models include detailed representations for the split hybrid system, the vehicle ICE and electric motor. The developed models were simulated in ADVISOR. Using the proposed vehicle controller, the vehicle can be operated in different modes of operation depending on the driving conditions. The transient response of each mode is also studied in this paper. By applied the modelling and working in different modes of operation, the engine operates in more efficient areas of the efficiency map which implies a higher efficiency in comparison to the conventional drive-trains.

The developed platform can be used for real-time simulation of the drive-train and also for hardware-in-the-loop simulation of the vehicle if implemented on a real-time simulator such as ADVISOR.

The authors would like to be obliged to Universiti Malaysia Pahang for providing laboratory facilities and financial assistance under project no. RDU150340.

\section{References}

1. Z.A. Saiful, N. Saad, S.Mohd, and A. Rashid A. Aziz. "Split-Parallel In-Wheel-Motor Retrofit Hybrid Electric Vehicle". IEEE International Power Engineering and Optimization Conference (PEOCO), Melaka, Malaysia: 6-7 (2012).

2. J. B. Steven "Hybrid Electric Vehicle Control Strategy Based on Power Loss Calculations". Virginia Polytechnic Institute and State University Master of Science Mechanical Engineering (2006).

3. D. W. Gao, Senior Member IEEE, Chris Mi, Senior Member IEEE, and Ali Emadi, Senior Member IEEE. Modeling and Simulation of Electric and Hybrid Vehicles". Gao et al.: Modelling and Simulation of Electric and Hybrid Vehicles, 95, No. 4, Proceedings of the IEEE (2007).

4. K. B. Wipke, M. R. Cuddy, and S. D. Burch. Nov. "ADVISOR 2.1: A user-friendly advanced powertrain simulation using a combined backward/forward approach". IEEE Trans. Vehicular Technol., 48, pp. 1751-1761 (1999).

5. T. Markel, A. Brooker, T. Hendricks, V. Johnson, K. Kelly, B. Kramer, M. O’Keefe, S. Sprik, and K.Wipke.." ADVISOR: A systems analysis tool for advanced vehicle modeling". J. Power Sources, vol. 110, no. 2, pp. 255-266 (2002)

6. Ansoft Simplorer Website. [Online]. Available: http://www.ansoft.com/.

7. Saber Website. [Online]. Available: http://www.synopsys.com/saber/.

8. W. Gao. "Performance comparison of a hybrid fuel cell Battery powertrain and a hybrid fuel cell Ultracapacitor powertrain”. IEEE Trans. Vehicular Technol., vol. 54, no. 3, pp. 846-855 (2005).

9. A. C. Baisden and A. Emadi. "An ADVISOR based model of a battery and an ultracapacitor energy source for hybrid electric vehicles". IEEE Trans. Vehicular Technol., vol. 53, no. 1 (2004).

10. M. I. M. Rashid, H. Daniyal. "Modelling And Simulation Of Split Plug-In Hybrid Electric Vehicle Using Advisor". ARPN Journal of Engineering and Applied Sciences, Vol. 10, No. 21, pp. 9860-9865 (2015). 